\title{
ERAS Pathway: Need of the Hour in Gynecological Malignancies
}

\author{
Geetu Bhandoria ${ }^{1}$. S. P. Somashekhar ${ }^{2}$
}

Published online: 10 June 2020

(C) Association of Gynecologic Oncologists of India 2020

\section{ERAS Approach: Need of the Hour}

Enhanced recovery after surgery (ERAS) is firmly established as a global surgical quality improvement pathway [1]. The results are in terms of both improved clinical outcomes and reduced hospital stay, translating ultimately into reduced health-care costs [2]. It is estimated that 234 million surgeries are performed globally annually [3]. Among these patients, 1 in $5[4,5]$ is expected to suffer post-surgical complications that are known to increase morbidity, hospital length of stay and cost and decrease long-term survival $[5,6]$. Professor Henrik Kehlet, professor of perioperative therapy at Rigshospitalet, Copenhagen University, introduced the concept of enhanced recovery pathway in 2002 [7]. This approach was previous called as 'Fast Track (FT) surgery' or 'Enhanced Recovery Programs.' This multimodal FT surgery care team requires not only surgeons but also anesthesiologists, nurses and physiotherapists $[8,9]$.

Multiple evidence-based perioperative care elements are present which have the potential to decrease post-surgical complications by up to 50\% [10], length of stay by $30 \%$ [10] and overall costs $[11,12]$. Together, these elements form the basis of published enhanced recovery after surgery (ERAS) guidelines [13] now implemented in over 20 countries [1]. Such twenty-one guidelines exist as of today, in various surgical specialties and sub-specialties. [14]. There is an international society, ERAS society, that leads the way in developing and updating ERAS guidelines and has regular meets at various national and international levels [15]. The society was initially called ERAS study group, originated in 2001 by Professor Ken Fearon of University of Edinburgh, UK, and Professor Olle

Geetu Bhandoria

doctor_071277@yahoo.co.in

1 Department of Obstetrics and Gynecology/GynecologyOncology, Command Hospital and Armed Forces Medical College, Pune 411040, India

2 Manipal Comprehensive Cancer Center, Manipal Hospital, Bengaluru, India
Ljungqvist of Karolinska Insitutet, Sweden. ERAS society was officially formed in 2010 in Stockholm, Sweden [15]. The first ERAS Implementation program was run in Sweden from Örebro University Hospital.

The original ERAS question, posed by Prof Henrik Kehlet in 1997, was whether mitigation of the surgical stress response led to accelerated convalescence and improved surgical outcomes. Dr. Kehlet's work focused largely on patient education and activation and attenuation of the surgical stress response through aggressive pain relief modalities, early mobilization and early enteral nutrition [16]. The global health-care community has come a long way since, with numerous surgical centers adopting ERAS protocols. These protocols are basically divided in three parts: preoperative, intraoperative and postoperative.

\begin{tabular}{|c|c|c|}
\hline Preoperative & Intraoperative & Postoperative \\
\hline $\begin{array}{l}\text { Patient and career } \\
\text { education relative } \\
\text { to their roles and } \\
\text { expected } \\
\text { milestones within } \\
\text { the enhanced } \\
\text { recovery pathway }\end{array}$ & $\begin{array}{l}\text { Assure multimodal, } \\
\text { narcotic-sparing } \\
\text { analgesia including } \\
\text { regional anesthesia }\end{array}$ & $\begin{array}{l}\text { Assure pain } \\
\text { management is } \\
\text { adequate to allow } \\
\text { for early } \\
\text { ambulation }\end{array}$ \\
\hline $\begin{array}{l}\text { Individualized } \\
\text { patient risk- } \\
\text { assessment }\end{array}$ & $\begin{array}{l}\text { Assure multimodal } \\
\text { postoperative } \\
\text { nausea and } \\
\text { vomiting } \\
\text { prophylaxis }\end{array}$ & $\begin{array}{l}\text { Assure continued } \\
\text { postoperative } \\
\text { nausea and } \\
\text { vomiting } \\
\text { management to } \\
\text { allow for early } \\
\text { alimentation }\end{array}$ \\
\hline $\begin{array}{l}\text { Optimize medical } \\
\text { management }\end{array}$ & $\begin{array}{l}\text { Assure goal-directed } \\
\text { fluid therapy } \\
\text { including goal- } \\
\text { directed hemostasis } \\
\text { management }\end{array}$ & $\begin{array}{l}\text { Postoperative patient } \\
\text { follow-up including } \\
\text { the post-acute care } \\
\text { phase }\end{array}$ \\
\hline $\begin{array}{l}\text { Ensure } 12.5 \% \\
\text { carbohydrate } \\
\text { beverage loading } \\
\text { within } 2 \mathrm{~h} \text { of } \\
\text { surgery }\end{array}$ & $\begin{array}{l}\text { Assure that } \\
\text { appropriate } \\
\text { standard measures } \\
\text { have been } \\
\text { completed } \\
\text { including } \\
\text { maintenance of } \\
\text { normothermia }\end{array}$ & $\begin{array}{l}\text { Audit all steps for } \\
\text { compliance, review } \\
\text { and process } \\
\text { improvement }\end{array}$ \\
\hline
\end{tabular}


(continued)

\begin{tabular}{lll}
\hline Preoperative & Intraoperative & Postoperative \\
\hline Ensure adherence to & - & - \\
ASA nil-by-mouth & & \\
guidelines allowing & & \\
for clear liquid & \\
consumption until & \\
$2 \mathrm{~h}$ prior to surgery & \\
\hline
\end{tabular}

Preoperative assessment marks the beginning of enhanced recovery protocol. This helps in triage of highrisk patients and provides an opportunity to 'optimize' any medical or surgical conditions that may affect outcome of surgery. This has also been termed as 'Prehabilitation.' Several interventions have been included like patient's information, education and counseling; aerobic and resistance exercises to improve physical status; nutritional interventions like high-protein diet [17]. One of key changes in preoperative preparation of surgical patients has been foregoing mechanical bowel preparation. Several randomized trials as well as meta-analysis have conclusively proven that omitting bowel preparation reduces surgical site infection (7.2\% vs $16 \%$ ) as well as hospital length of stay [17]. The concept of preoperative fasting has also been toned down in light of new evidence, with clear fluids been safely given up to $2 \mathrm{~h}$, and a light meal up to $6 \mathrm{~h}$, before elective procedures requiring general anesthesia, in children and adults, are currently recommended. This mitigates the surgical stress and marked postoperative metabolic response [17].

Intraoperative measures include venous thrombo-embolism prophylaxis (combination of mechanical measures such as pneumatic compression devices, pharmacological anti-coagulation with low molecular weight heparin, unfractionated heparin or direct-acting oral anticoagulants). Extended (28-day) anticoagulation is now recommended in high-risk cases [17]. Surgical site infections (SSIs) are one of commonest postoperative complications encountered in surgical population. Several SSI reduction bundles have been suggested and are an integral part of enhanced care pathways. The main components are antimicrobial prophylaxis with appropriate antibiotics, cephalosporins commonly; skin preparation by chlorhexidine-based soap shower prior to surgery and chlorhexidine-alcohol skin preparation in operating room; prevention of perioperative hypothermia by active intraoperative warming, using prewarmed parenteral fluids; avoidance of drains/tubes routinely, though strong evidence for same lacks presently; control of perioperative hyperglycemia, which has been found to have effects on mortality [17].

There are subset of guidelines for anesthetists; in fact a 'champion' anesthetist is an integral part of ERAS algorithm, just as a 'champion nurse' and a 'champion surgeon' are. They comprise the three pillars of success of an enhanced recovery pathway. The use of short-acting anesthetics, monitoring of neuromuscular block depth and complete reversal are recommended. Ventilation should use a protective strategy with tidal volumes $6-8 \mathrm{~mL} / \mathrm{kg}$ and positive end expiratory pressure $6-8 \mathrm{~cm} \mathrm{H}_{2} \mathrm{O}$ [17]. Minimal invasive surgical techniques are recommended to be used whenever feasible due to largely proven benefits in earlier postoperative recovery.

One of the most important components of an ERAS program is the use of goal-directed fluid therapy; this may be facilitated by the use of minimally invasive hemodynamic monitoring to detect flow-related parameters and/or dynamic parameters of fluid responsiveness. This is done in order to titrate therapeutic interventions (intravenous fluids and/or inotropic therapy administration) to optimize end organ tissue perfusion [18]. Goal-directed fluid therapy in ERAS pathways is simpler to implement as compared with patients on traditional surgical pathways. This is because patients on an ERAS pathway are not exposed to prolonged periods of fasting, or mechanical bowel preparations, and, in addition, are given carbohydrate loading solutions the night before and the morning of surgery, allowing for better hydration and a normal intravascular volume status [17].

A multimodal postoperative analgesic protocol has been recommended to reduce overall opioid administration. This is usually achieved by non-opioid oral medicines and local injection of anesthetic agents at incisional site. 'Early feeding' has been found to improvements in return of bowel activity, reduced length of hospital stay and equivalent complication rates as measured by wound healing, anastomotic leaks, or pulmonary complications [19]. Highprotein diet especially has been found to enhance recovery after surgery. Early feeding also prevents and reduces risk of postoperative ileus, the risk of which could be as high as $30 \%$, especially in cancer surgeries. Postoperative coffee consumption has been found to reduce these rates by as low as $10 \%$ [20].

There has been a lot of buzz lately to include patients' perspectives in analyzing outcome of any clinical trial. In fact, 'patient-reported outcomes' are an integral part of ERAS programs now. The recovery process is complex and encompasses the multiple dimensions of physical, emotional, economic and social health [21]. Consistent collection and documentation of patient-reported outcomes within ERAS programs allow institutions to monitor, understand and compare functional recovery in a patientcentered fashion [17]. Patients managed under ERAS pathway are discharged in an intermediate recovery phase, with the recovery process expected to extend into the home setting. Patients are thus given detailed education about recovery process, to avoid unplanned hospital visits. 
Implementation of ERAS requires coordination by a multidisciplinary team spanning the entire continuum of care from preoperative counseling to return to normal function. Assessing adherence to specific ERAS elements is an essential component of an ERAS program. To improve the quality of ERAS reporting, ERAS USA and the ERAS Society have published the Reporting on ERAS Compliance, Outcomes, and Elements Research (RECOvER) Checklist. Clinicians are encouraged to use ERAS auditing tools. Two examples include the ERAS interactive audit system (EIAS) (https://erassociety.org/ interactive-audit/) and the Agency for Healthcare Research and Quality (AHRQ) safety program for improving surgical care and recovery (https://www.ahrq.gov/professionals/ quality-patient-safety/hais/tools/enhanced-recovery/index. html) [17]. To conclude, ERAS program continues to expand across various surgical disciplines as this editorial is written. Switching to and adopting these guidelines have been proved to improve patient outcomes and reduce health-care costs whether to state or individual patients.

Funding Nil.

\section{Compliance with ethical standards}

Conflict of interest The authors declare that they have no conflict of interest.

Ethical issues Nil.

\section{References}

1. Ljungqvist $\mathrm{O}$, Scott M, Fearon KC. Enhanced recovery after surgery: a review. JAMA Surg. 2017;152:292-8.

2. Ljungqvist $O$, Thanh NX, Nelson G. ERAS-Value based surgery. J Surg Oncol. 2017;116:608-12.

3. Weiser TG, Regenbogen SE, Thompson KD, Haynes AB, Lipsitz SR, Berry WR, Gawande AA. An estimation of the global volume of surgery: a modelling strategy based on available data. Lancet. 2008;372(9633):139-44.

4. Ghaferi AA, Birkmeyer JD, Dimick JB. Variation in hospital mortality associated with inpatient surgery. $\mathrm{N}$ Engl $\mathrm{J}$ Med. 2009;361(14):1368-75.

5. Pucher PH, Aggarwal R, Qurashi M, Darzi A. Meta-analysis of the effect of postoperative in-hospital morbidity on long-term patient survival. Br J Surg. 2014;101(12):1499-508.
6. Khuri SF, Henderson WG, DePalma RG, Mosca C, Healey NA, Kumbhani DJ, Participants in the VA National Surgical Quality Improvement Program. Determinants of long-term survival after major surgery and the adverse effect of postoperative complications. Ann Surg. 2005;242(3):326-41 (discussion 341-3).

7. Moonesinghe SR, Harris S, Mythen MG, Rowan KM, Haddad FS, Emberton M, Grocott MP. Survival after postoperative morbidity: a longitudinal observational cohort study. $\mathrm{Br} \mathrm{J}$ Anaesth. 2014;113(6):977-84.

8. Kehlet H, Wilmore DW. Multimodal strategies to improve surgical outcome. Am J Surg. 2002;183:630-41.

9. Kehlet H, Dahl JB. Anaesthesia, surgery, and challenges in postoperative recovery. Lancet. 2003;362(9399):1921-8.

10. Greco M, Capretti G, Beretta L, Gemma M, Pecorelli N, Braga M. Enhanced recovery program in colorectal surgery: a metaanalysis of randomized controlled trials. World J Surg. 2014;38(6):1531-41.

11. Miller TE, Thacker JK, White WD, Mantyh C, Migaly J, Jin J, Roche AM, Eisenstein EL, Edwards R, Anstrom KJ, Moon RE, Gan TJ, Enhanced Recovery Study Group. Reduced length of hospital stay in colorectal surgery after implementation of an enhanced recovery protocol. Anesth Analg. 2014;118(5):1052-61.

12. Ebm C, Cecconi M, Sutton L, Rhodes A. A cost-effectiveness analysis of postoperative goal-directed therapy for high-risk surgical patients. Crit Care Med. 2014;42(5):1194-203.

13. Gan TJ, Thacker JK, Miller TE, Scott MJ, Holubar SD. Enhanced recovery for major abdominopelvic surgery. 1st ed. New York: Professional Communications Inc.; 2016.

14. https://erassociety.org/guidelines/list-of-guidelines.

15. https://erassociety.org.

16. Kehlet H. Multimodal approach to control postoperative pathophysiology and rehabilitation. Br J Anaesth. 1997;78(5):606-17.

17. Nelson G, Bakkum-Gamez J, Kalogera E, et al. Guidelines for perioperative care in gynecologic/oncology: enhanced recovery after surgery (ERAS) Society recommendations-2019 update. Int J Gyn Cancer. 2019;29:651-68.

18. Miralpeix E, Nick AM, Meyer LA, et al. A call for new standard of care in perioperative gynecologic oncology practice: impact of enhanced recovery after surgery (ERAS) programs. Gynecol Oncol. 2016;141:371-8.

19. Minig L, Biffi R, Zanagnolo V, et al. Reduction of postoperative complication rate with the use of early oral feeding in gynecologic oncologic patients undergoing a major surgery: a randomized controlled trial. Ann Surg Oncol. 2009;16:3101-10.

20. Güngördük K, Özdemir İA, Güngördük Ö, et al. Effects of coffee consumption on gut recovery after surgery of gynecological cancer patients: a randomized controlled trial. Am J Obstet Gynecol. 2017;216:145.e1-.e7.

21. Lee L, Tran T, Mayo NE, et al. What does it really mean to "recover" from an operation? Surgery. 2014;155:211-6.

Publisher's Note Springer Nature remains neutral with regard to jurisdictional claims in published maps and institutional affiliations. 